\title{
Simulasi Prediksi Tekanan Kontak pada Permukaan Acetabular Cup dengan Aplikasi Permukaan Bertekstur pada Total Hip Arthroplasty
}

\author{
Muhammad Imam Ammarullah ${ }^{1,4}$, Amir Putra Md Saad ${ }^{2,3}$, Ardiyansyah Syahrom ${ }^{2,3}$ Hasan Basri $^{1, *}$, Jamari $^{4}$ \\ ${ }^{1}$ Jurusan Teknik Mesin, Fakultas Teknik, Universitas Sriwijaya \\ Indralaya 30662, Ogan Ilir, Sumatera Selatan, Indonesia \\ ${ }^{2}$ Jurusan Aplikasi Mekanik dan Desain, Fakultas Teknik Mesin, Universiti Teknologi Malaysia \\ ${ }^{3}$ Medical Device and Technology Center, Institute of Human Centered Engineering, Universiti Teknologi Malaysia \\ Skudai 81310, Johor, Malaysia \\ ${ }^{4}$ Jurusan Teknik Mesin, Fakultas Teknik, Universitas Diponegoro \\ Tembalang 50275, Semarang, Jawa Tengah, Indonesia \\ *E-mail: hasan_basri@unsri.ac.id
}

\begin{abstract}
Abstrak
Kajian ini bertujuan untuk menganalisa tekanan kontak pada permukaan acetabular cup dengan dan tanpa aplikasi permukaan bertekstur. Kontribusi utama dari studi ini adalah mempelajari efek penambahan dimple terhadap tekanan kontak yang berkorelasi terhadap keausan yang terjadi. Pendekatan dengan menggunakan perangkat lunak dilakukan dengan melakukan pemuatan fisiologis sambungan tulang pinggul secara 3D dalam kondisi berjalan normal. Analisa tekanan kontak dilakukan secara kontak langsung dan deskritasi elemen hingga dengan metode dua kutub dilakukan untuk memberikan hasil tekanan kontak yang akurat. Hasil menunjukkan bahwa model total hip arthroplasty dengan penambahan dimple dapat mengurangi tekanan kontak untuk seluruh fase dalam satu siklus penuh yang menjelaskan bahwa penambahan dimple pada permukaan acetabular cup di total hip artroplasti dapat mengurangi tekanan kontak dan mengurangi keausan.
\end{abstract}

Diterima: 11-10-2020; Direvisi: 05-11-2020; Dipublikasi: 28-12-2020

Kata kunci: acetabular cup; dimple; permukaan bertekstur; tekanan kontak; total hip arthroplasty

\begin{abstract}
This study aims to analyze the contact pressure on the surface of acetabular cups with and without textured surface application. The main contribution of this study is to study the effect of adding dimple on contact pressure which correlates with the wear occurs. Approach using the software is done by doing physiological loading of the hip joint in $3 D$ under normal walking conditions. Contact pressure analysis is carried out by direct contact and finite element descritation using the two-pole method is carried out to provide accurate contact pressure results. The results show that the total hip arthroplasty model with the addition of dimples can reduce the contact pressure for all phases in one full cycle which explains that adding dimples to the acetabular cup surface in total hip arthroplasty can reduce contact pressure and reduce wear.
\end{abstract}

Keywords: acetabular cup; dimple; textured surface; contact pressure; total hip arthroplasty

\section{Pendahuluan}

Penggunaan permukaan bertekstur telah mendapatkan perhatian khusus dalam penerapannya pada komponen mekanika seperti bantalan aksial, bantalan luncur, bantalan jurnal, cincin piston, perapat mekanik, mata pahat mesin perkakas serta berbagai aplikasi lainnya [1]. Dalam bidang alat implan, aplikasi permukaan bertekstur pada total hip arthroplasty telah mulai dilakukan pada permukaan bantalan pasang yang berkontak dengan penambahan dimple [2]. Berdasarkan literatur yang tersedia, dimple mengurangi luas permukaan yang berkontak berdampak pada menurunnya keausan adhesi dan koefisien gesek. Penambahan dimple juga berfungsi untuk menjebak partikel aus, sehingga mencegah keausan abrasif dari permukaan kontak oleh partikel keras pihak ketiga (third body) serta menghasilkan tekanan hidrodinamik untuk memberikan daya angkat tambahan [3]. Berbagai penelitian juga telah menunjukkan efek positif penambahan dimple pada bantalan pasang yang dapat meningkatkan performansi tribologikal yang telah terbukti secara 
teori maupun eksperimental [4]. Namun hingga saat ini, pengaruh penambahan dimple terhadap tekanan kontak pada total hip arthroplasty masih belum memberikan deskripsi yang lebih rinci dalam penjelasannya dari peneliti terdahulu.

Metode elemen hingga sebagai alat komputasi yang akurat untuk analisa tekanan kontak dilaporkan telah banyak digunakan untuk oleh peneliti-peneliti terdahulu untuk memangkas biaya yang mahal serta meminimalisir jangka waktu yang lama untuk uji coba dan studi laboratorium. Namun dengan kelebihan yang ditawarkan, masih banyak peneliti yang menggunakan metode elemen hingga dengan model dan pembebanan yang disederhanakan. Melihat pada penelitian terdahulu pada total hip arthroplasty, Basri dkk. [2, 5] melakukan analisa pengaruh variasi geometri pada penambahan dimple terhadap performansi lubrikasi menggunakan metode elemen hingga, namun penelitian tersebut tidak memfokuskan analisa pada tekanan kontak serta model elemen hingga yang dipresentasikan sangat disederhanakan, serta pemberian gaya yang masih menggunakan beban $2 \mathrm{D}$ yang tidak memenuhi kondisi fisiologis sambungan tulang pinggul. Selain itu Shankar dkk. [6] melakukan prediksi tekanan kontak dan keausan dengan menggunakan pembebanan yang tidak disederhanakan, namun penambahan dimple dan pengaruhnya belum dilakukan. Selain itu, penelitian tersebut menggunakan model elemen hingga berbentuk 2D yang disederhanakan, dimana hal tersebut dapat mengurangi akurasi hasil yang didapatkan.

Penelitian ini bertujuan untuk menganalisa tekanan kontak pada permukaan acetabular cup dengan dan tanpa penambahan dimple. Hal ini dilakukan secara kontak kering dengan model 3D dan pembebanan yang tidak disederhanakan untuk hasil yang lebih akurat. Komparasi hasil tekanan kontak untuk total hip arthroplasty tanpa dan dengan penambahan dimple dilakukan. Serta pengembangan model elemen hingga secara 3D untuk total hip arthroplasty dengan penambahan dimple telah penulis lakukan sebagai keterbaharuan dalam penelitian ini, dikarenakan belum ada peneliti manapun yang telah berhasil membuat model elemen hingga untuk total hip arthroplasty dengan penambahan dimple.

\section{Material dan metodologi}

\subsection{Parameter Geometri dan Material}

Dalam penelitian ini, geometri dari total hip arthroplasty, baik untuk komponen femoral head dan acetabular cup mengacu pada penelitian sebelumnya yang dilakukan oleh Uddin dan Zhang [7] dengan rincian: diameter femoral head, clearance, dan ketebalan acetabular cup masing-masing $28 \mathrm{~mm}, 55 \mu \mathrm{m}$, dan $5 \mathrm{~mm}$. Penambahan dimple pada total hip arthroplasty mengacu pada penelitian sebelumnya yang dilakukan oleh Choudhury dkk. [8] dengan rincian parameter penambahan dimple: diameter, kedalaman, bentuk, pola, jumlah, jarak, daerah penambahan masing-masing 0,26 mm, 0,03 mm, bulat, melingkar, 6, 91. 0,49 mm, dan permukaan kontak femoral head. Kombinasi material yang digunakan untuk femoral head dan acetabular cup berjenis metal-on-metal dengan menggunakan Cobalt Chromium Molybdenum yang diasumsikan homogen mengacu pada penelitian sebelumnya yang dilakukan oleh Jhurani dkk. [9].

\subsection{Pemodelan Elemen Hingga}

Simulasi prediksi keausan diwakilkan oleh komponen femoral head dan acetabular cup sebagai komponen utama dalam analisa untuk meminimalisir lama waktu simulasi dan penggunaan ruang penyimpanan yang lebih sedikit. Pemodelan elemen hingga dari total hip arthroplasty menggunakan model 3D ball-in-socket yang dijelaskan pada Gambar 1, dengan asimetris pada komponen femoral head $[7,10]$. 


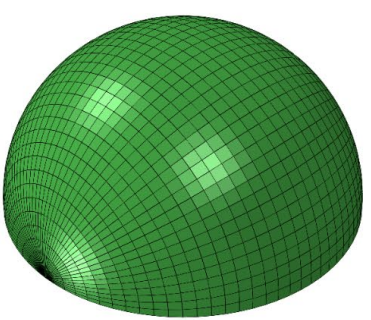

Tanpa penambahan dimple

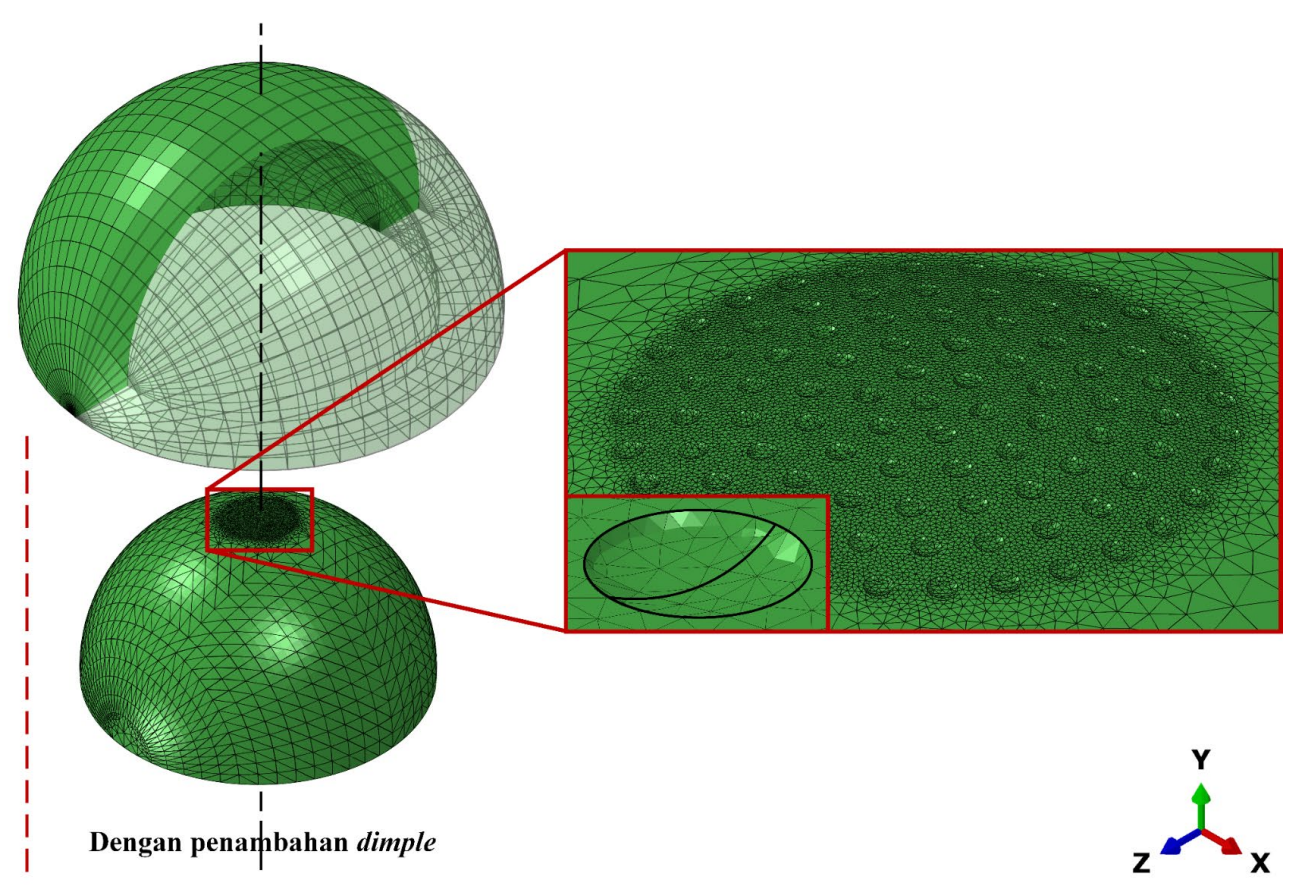

Gambar 1. Model elemen hingga dengan dan tanpa penambahan dimple

\subsection{Penentuan Kondisi Batas}

Kondisi batas pada simulasi total hip arthroplasty penting untuk ditentukan agar dapat mensimulasikan objek sesuai dengan kondisi nyata. Kondisi batas diberikan pada komponen acetabular cup dan femoral head. Pada acetabular cup, kondisi batas diberikan dengan membuat objek tidak bergerak dengan cara membuat fully constrained seluruh permukaan luar acetabular cup yang didasarkan karena pada kondisi nyata acetabular cup menempel pada acetabulum dan membuatnya tidak dapat bergerak. Pengaruh benda ketiga selama simulasi diabaikan. Selanjutnya, untuk penentuan kondisi batas pada femoral head diberikan pembatasan rentang gerak yang didasarkan karena pada kondisi nyata, femoral head mengartikulasi pada permukaan acetabular cup memiliki rentang gerak yang terjadi sesuai dengan aktifitas yang dilakukan.

\subsection{Siklus Gait}

Berbagai studi melaporkan, pembebanan yang diberikan dalam simulasi prediksi tekanan kontak pada total hip arthroplasty adalah pembabanan sambungan tulang pinggul dalam kondisi berjalan normal [11]. Hal tersebut dikarenakan aktifitas manusia sehari-hari yang paling dominan dilakukan pada sambungan tulaang pinggul adalah kegiatan berjalan normal. Pendekatan yang dilakukan untuk siklus gait dalam kondisi berjalan normal dengan kondisi 3D yang mewakili kondisi fisiologis ssambungan tulang pinggul seutuhnya merujuk pada penelitian sebelumnya yang dilakukan oleh Bergman dkk. [12] dengan membagi satu fasenya menjadi 32 siklus. Gait loading dalam kondisi berjalan normal masingmasing dijelaskan pada Gambar 2. 


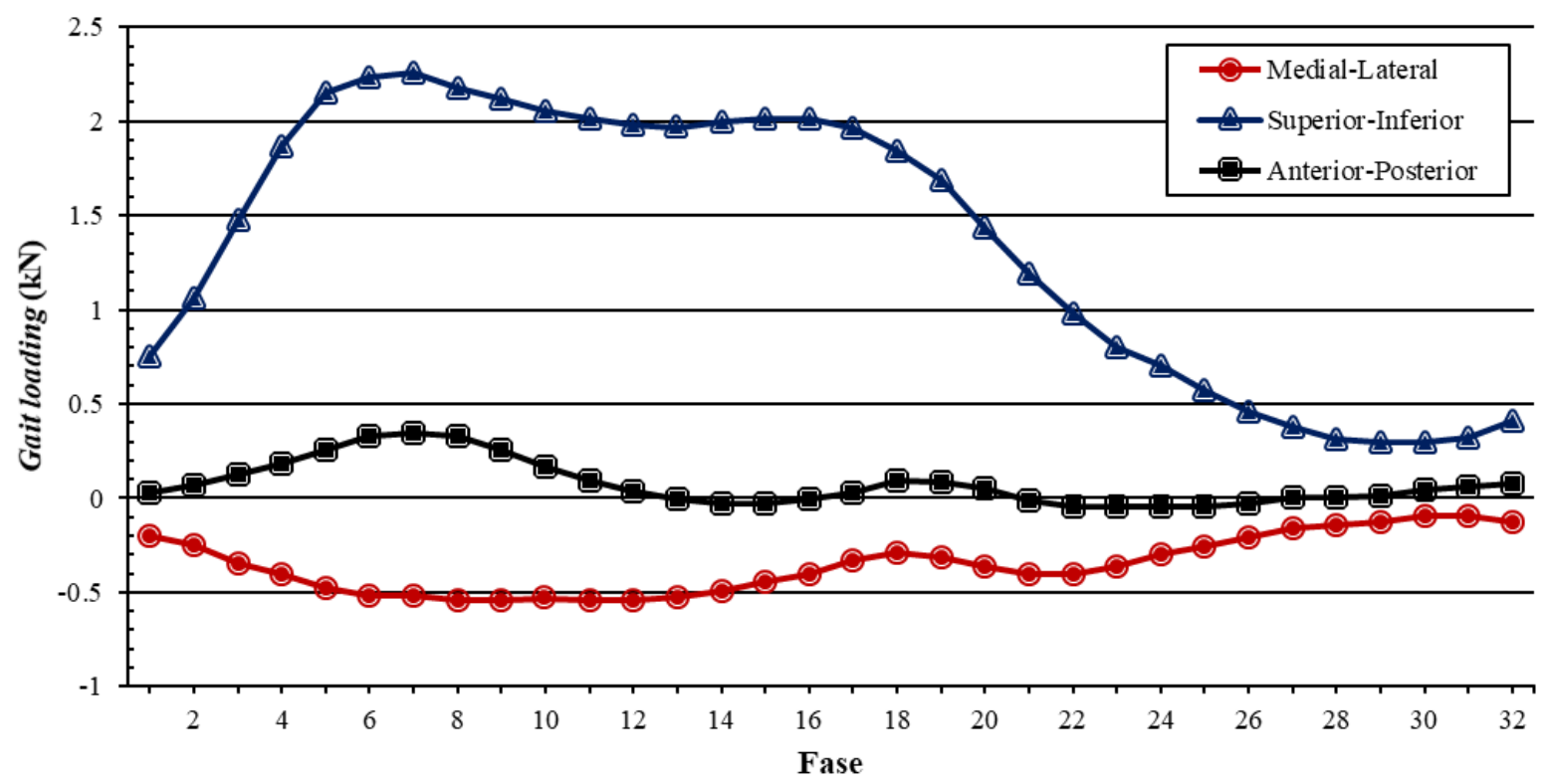

Gambar 2. Gait loading dalam kondisi berjalan normal

\subsection{Mekanika Kontak}

Parameter utama yang ditentukan dari mekanika kontak adalah tekanan kontak dan area kontak, yang mana ditunjukkan bahwa tegangan kontak berhubungan langsung dengan keausan lelah dan kerusakan permukaan kontak [13]. Dalam mekanika kontak, hubungan sederhana ini dapat digunakan dimana tekanan kontak (P) adalah beban yang diberikan $\left(F_{n}\right)$ dibagi dengan luas area kontak $(A)$ pada Persamaan (1) [14].

$$
\mathrm{P}=\frac{\mathrm{F}_{\mathrm{n}}}{\mathrm{A}}
$$

\section{Hasil dan pembahasan}

\subsection{Validasi Tekanan Kontak}

Validasi tekanan kontak dilakukan dengan penelitian yang dilakukan oleh Uddin dan Zhang [7] untuk model total hip arthroplasty tanpa penambahan dimple, sedangkan untuk model dengan penambahan dimple tidak dilakukan karena tidak memiliki penelitian yang dapat dijadikan sebagai validasi tekanan kontak. Dalam penelitian sebelumnya sebagai validasi tekanan kontak, nilai tekanan kontak tertinggi berada pada fase ke-7 dengan nilai 78.567 MPa, sedangkan untuk nilai tekanan kontak tertinggi yang didapatkan oleh penulis berada pada fase ke-7 dengan nilai $80.75 \mathrm{MPa}$. Persentase error dicari untuk melihat kesesuaian hasil antar keduanya dan didapatkan persentase kesalahan sebesar 2.7\% yang memenuhi kriteria validasi tekanan kontak dengan persentase kesalahan $<5 \%$ sehingga dianggap sesuai dan dapat dilanjutkan ke tahap analisa tekanan kontak. Validasi tekanan kontak dijelaskan pada Gambar 3. 

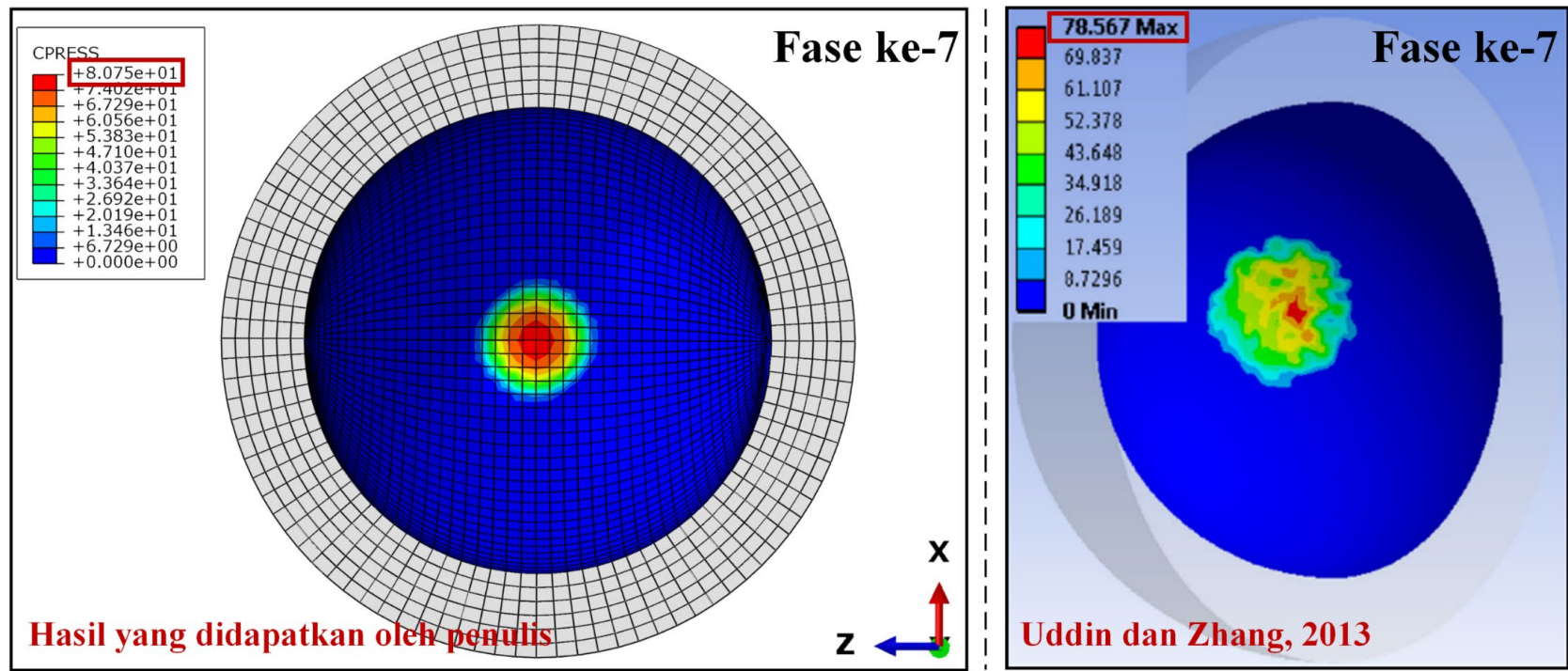

Gambar 3. Validasi tekanan kontak

\subsection{Analisa Tekanan Kontak}

Setelah melewati satu siklus pembebanan berjalan normal dengan jumlah 32 fase, didapatkanlah nilai tekanan kontak di permukaan acetabular cup pada total hip arthroplasty dengan dan tanpa penambahan dimple. Analisa tekanan kontak dari kedua model dijelaskan pada Gambar 4.

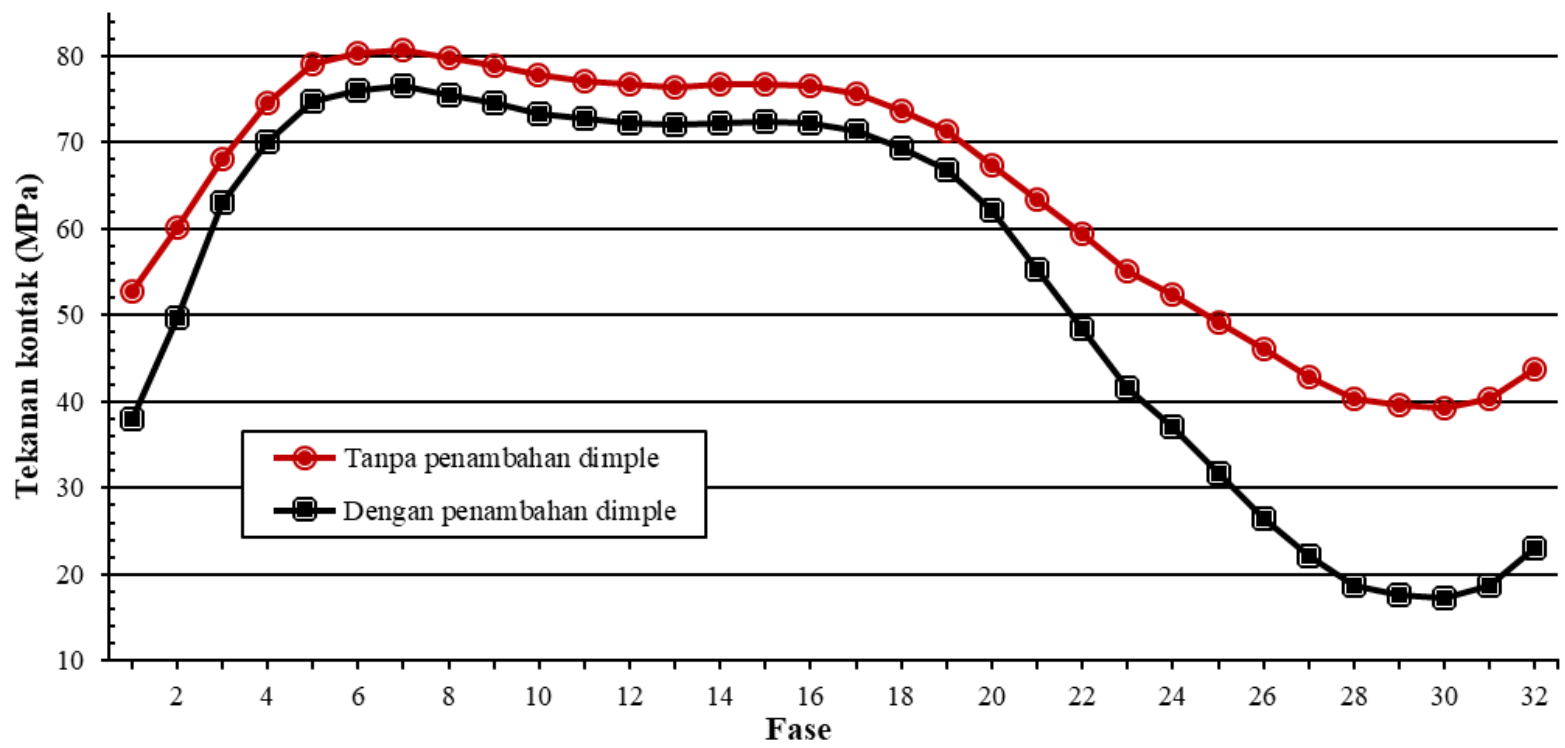

Gambar 4. Analisa tekanan kontak

Berdasarkan Gambar 4, dapat kita lihat model total hip arthroplasty tanpa penambahan dimple dalam satu siklus penuh memiliki nilai tekanan kontak yang lebih tinggi untuk seluruh fase bila dibandingkan dengan model total hip arthroplasty dengan penambahan dimple. Hal ini dikarenakan penambahan dimple pada permukaan femoral head membuat area yang berkontak langsung dengan acetabular cup berkurang dan memperluas permukaan nyata dari femoral head sehingga memperkecil tekanan kontak yang terjadi pada acetabular cup [14]. Analisa tekanan kontak dalam penelitian ini berhasil menunjukkan pengurangan tekanan kontak dengan penambahan dimple pada daerah yang 
berkontak. Dengan melihat dalam persamaan keausan Archard [15] dimana salah satu faktor yang mempengaruhi keausan adalah tekanan kontak. Dengan mengurangi tekanan kontak maka keausan akan berkurang sehingga dapat memperpanjang lama penggunaan alat implan.

\section{Kesimpulan}

Penelitian ini telah melakukan analisa elemen hingga untuk tekanan kontak total hip arthroplasty tanpa dan dengan penambahan dimple secara kontak kering dibawah kondisi pemuatan fisiologis secara 3D dalam siklus berjalan normal. Karena siklus pembebanan, intensitas dan lokasi tekanan kontak maksimum dalam komponen bantalan berubah sesuai dengan fase pembebanan, dengan yang tertinggi pada fase ke-7. Didapatkan bahwa penambahan dimple pada total hip arthroplasty dapat mengurangi tekanan kontak pada seluruh fase dalam satu siklus. Validasi juga telah dilakukan dengan penelitian yang telah dilakukan sebelumnya, penulis menemukan bahwa model analisa tekanan kontak dalam penelitian ini dapat memberikan prediksi yang rasional.

\section{Ucapan terima kasih}

Penulis mengucapkan terimakasih kepada Medical Device and Technology Center, Institute of Human Centered Engineering, Universiti Teknologi Malaysia atas kolaborasi dalam menjalankan penelitian ini dan Universitas Sriwijaya sebagai institusi penulis yang memberikan pendanaan penelitian.

\section{Daftar Pustaka}

[1] Ammarullah, M.I., Analisis Pengaruh Variasi Bottom Profile Dimple di Permukaan Femoral Head terhadap Keausan pada Total Hip Arthroplasty. Indonesia: Universitas Sriwijaya; 2019. p. 3

[2] Basri, H., Syahrom, A., Prakoso, A.T., Wicaksono, D., Amarullah, M.I., Ramadhoni, T.S., Nugraha, R.D., The Analysis of Dimple Geometry on Artificial Hip Joint to the Performance of Lubrication. Journal of Physics: Conference Series. 2019; 1198(4): p.1-10.

[3] Etsion, I., State of the art in laser surface texturing. Journal of Tribology. 2005; 127(1): p.248-53.

[4] Etsion, I., Modeling of surface texturing in hydrodynamic lubrication. Friction. 2013; 1(3): p.195-209.

[5] Basri, H., Syahrom, A., Ramadhoni, T.S., Prakoso, A.T., Ammarullah, M.I., Vincent., The analysis of the dimple arrangement of the artificial hip joint to the performance of lubrication. IOP Conference Series: Materials Science and Engineering. 2019; 620(1): p.1-10.

[6] Shankar, S., Siddarth, R., Nithyaprakash, R., Uddin, M.S., Wear prediction of hard carbon coated hard-on-hard hip implants using finite element method. International Journal of Computer Aided Engineering and Technology. 2018; 10(4): p.440-56.

[7] Uddin, M.S., Zhang, L.C., Predicting the wear of hard-on-hard hip joint prostheses. Wear. 2013; 301(1-2): p.192200.

[8] Choudhury, D., Vrbka, M., Mamat, A.B., Stavness, I., Roy, C.K., Mootanah, R., Krupka, I., The impact of surface and geometry on coefficient of friction of artificial hip joints. Journal of the Mechanical Behavior of Biomedical Materials. 2017; 72(May): p.192-9.

[9] Jhurani, S.M., Fred, Higgs C., An elastohydrodynamic lubrication (EHL) model of wear particle migration in an artificial hip joint. Tribology International. 2010; 43(8): p.1326-38.

[10] Harun, M.N., Wang, F.C., Jin, Z.M., Fisher, J., Long-term contact-coupled wear prediction for metal-on-metal 
total hip joint replacement. Proceedings of the Institution of Mechanical Engineers, Part J: Journal of Engineering Tribology. 2009; 223(7): p.993-1001.

[11] Dowson, D., McNie, C.M., Goldsmith, A.A.J., Direct experimental evidence of lubrication in a metal-on-metal total hip replacement tested in a joint simulator. Proceedings of the Institution of Mechanical Engineers, Part C: Journal of Mechanical Engineering. 2000; 214(1): p.75-86.

[12] Bergmann, G., Deuretzbacher, G., Heller, M., Graichen, F., Rohlmann, A., Hip contact and gait patterns from routine activities. Journal of Biomechanics. 2001; 34: p.859-71.

[13] McNie, C., Barton, D.C., Stone, M.H., Fisher, J., Prediction of plastic strains in ultra-high molecular weight polyethylene due to microscopic asperity interactions during sliding wear. Proceedings of the Institution of Mechanical Engineers, Part H: Journal of Engineering in Medicine. 1998; 212(1): p.49-56.

[14] Popov, V.L.. Contact mechanics and friction: Physical Principles and Aplication. Second Edi. Germany: Springer; 2017. P.10

[15] Archard, J.F., Contact and rubbing of flat surfaces. Journal of Applied Physics. 1953; 24(8): p.981-8. 